\title{
FAKTOR-FAKTOR YANG MEMENGARUHI KECEMASAN KEUANGAN PADA REMAJA KOTA SURABAYA
}

\author{
Jehan Sekarkinasih \\ Universitas Negeri Surabaya \\ Jehan.17080574094@mhs.unesa.ac.id
}

\begin{abstract}
This study is the first study in Indonesia that examines the factors that influence financial anxiety. Financial anxiety is a negative psychological impact where there is a decrease in various aspects so that, in total, it causes stress levels to jump. This study focuses on adolescents who live in Surabaya, which, based on BPS data, the city of Surabaya has the largest population in East Java and is dominated by adolescents. This study aims to determine the effect of income, debt, financial knowledge, and financial satisfaction on financial anxiety. Data were collected by distributing online questionnaires with random sampling methods to 154 respondents. Then, data were tabulated in excel, analyzed and processed using multiple linear regression in SPSS. The result of this study indicates that none of the independent variables affects financial anxiety. This is presumably due to the lack of public knowledge about financial anxiety, especially among Surabaya adolescents. Few studies examine financial anxiety as the dependent variable, which thought to cause limited public knowledge about this topic. Therefore, this study is expected to increase knowledge, literacy, and public awareness regarding financial anxiety, especially to adolescents in Surabaya.
\end{abstract}

Keywords: debt; financial anxiety, financial knowledge; financial satisfaction; income

\section{PENDAHULUAN}

World Health Organization (2018) menyatakan bahwa remaja berada pada kelompok usia 15-24 tahun mengalami transformasi pematangan fisik yang lebih cepat dibandingkan pematangan psikososialnya (Rahmawati, Rohaedi, and Sumartini, 2019). Proses transformasi dari masa kanak-kanak menuju dewasa menimbulkan polemik dalam diri remaja, seperti emosi tidak stabil, kemampuan penyelesaian masalah yang belum matang, dan pola pikir cenderung berubah-ubah (Yulianti, 2010). Fase remaja sangat rentan terhadap resiko yang berkenaan dengan kesehatan serta kesejahteraan jasmani dan rohani mereka (World Health Organization, 2018).

Gangguan kecemasan termasuk salah satu dari banyak jenis diagnosis klinis masalah mental emosional yang paling umum dijumpai pada masa kanak-kanak hingga remaja (Degnan, Almas, and Fox, 2010). Gangguan ini ditandai dengan munculnya rasa cemas atau khawatir secara berlebihan, tidak rasional, dan tidak realistis terhadap peristiwa yang ditemui dalam kehidupan sehari-hari maupun ketika terlibat aktivitas tertentu (Elvira and Hadisukanto, 2010; Shapiro and Burchell, 2012). Ross, Niebling, \& Heckert (1999) mengemukakan salah satu sumber kecemasan pada remaja adalah faktor intrapersonal, yakni rasa cemas yang timbul dari dalam diri sendiri berkaitan dengan perubahan pola makan dan tidur, penurunan kesehatan, serta kesulitan keuangan. Tingginya tingkat kesulitan, utamanya perihal keuangan, berpengaruh pada munculnya sakit kepala, kecemasan hingga depresi, pola hidup berantakan, gangguan tidur, perasaan tidak berdaya, bahkan sampai keinginan untuk mengakhiri hidup (Dixon et al., 1992; Oman et al., 2008).

Berdasarkan gambar 1, Surabaya merupakan Kota dengan jumlah penduduk terbanyak di Jawa Timur, yakni sebanyak 2.896.195 jiwa (BPS, 2019b). Jumlah tersebut didominasi oleh kelompok usia remaja 15-24 tahun dengan persentase 18\% dari keseluruhan penduduk Kota Surabaya atau sebanyak 518.782 jiwa (BPS, 2019a). Menurut laporan Riset Kesehatan Dasar (Riskesdas, 2019), prevalensi gangguan mental emosional (cemas, stres, dan depresi) paling umum terjadi pada remaja usia 15-24 tahun yakni sebesar 7,32\%, sedangkan prevalensi dengan gangguan mental emosional terendah berada pada kelompok usia 35-44 tahun (5,69\%). Hal ini menunjukkan bahwa remaja memiliki resiko lebih besar untuk mengalami gangguan mental emosional, termasuk gangguan kecemasan akibat kesulitan keuangan, dibandingkan ketika telah dewasa. 
Jehan Sekarkinasih. Faktor-Faktor yang Memengaruhi Kecemasan Keuangan pada Remaja Kota Surabaya

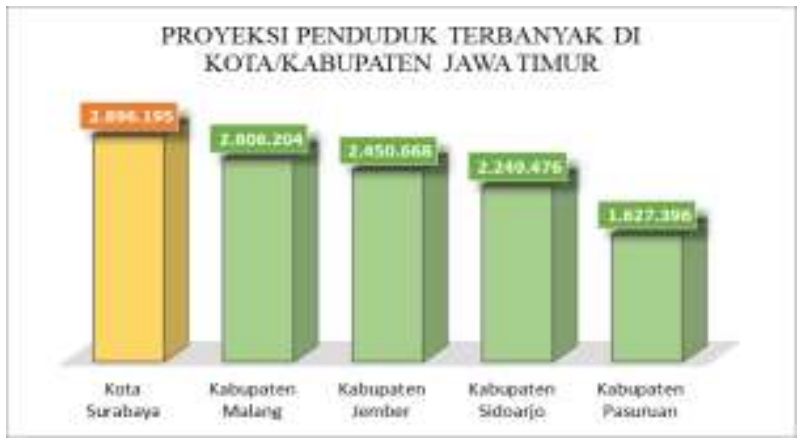

Sumber: BPS 2019

\section{Gambar 1. PROYEKSI KOTA/KABUPATEN DENGAN PENDUDUK TERBANYAK DI JATIM}

Kecemasan (anxiety) merupakan gejala normal yang umum dialami manusia, berupa keadaan emosi yang terasa tidak nyaman pada diri seseorang. Keadaan ini ditandai dengan munculnya rasa khawatir, prihatin, dan takut, pada tingkatan yang berbeda-beda (Yanti, Erlamsyah, and Zikra, 2013). Salah satu penyebab munculnya rasa cemas ialah ketika berhadapan dengan situasi kesulitan keuangan (Musabiq and Karimah, 2018). Rasa cemas akibat kondisi keuangan disebut kecemasan keuangan atau financial anxiety, yang mengacu pada perasaan cemas atau khawatir akan situasi keuangan yang sedang dihadapi seseorang (Archuleta, Dale, and Spann, 2013). Pada umumnya, ketika seseorang mengalami financial anxiety mereka cenderung akan menghindari dengan sengaja bahkan menolak hal-hal yang berkaitan dengan keuangan, seperti tidak membaca laporan bank, tidak memeriksa tingkat hutang maupun memikirkan upaya agar dapat membayar hutang di masa depan (Shapiro and Burchell, 2012). Terdapat empat faktor yang diduga memengaruhi tingkat financial anxiety yakni faktor pendapatan (income), utang (debt), pengetahuan keuangan (financial knowledge), dan kepuasan keuangan (financial satisfaction) (Shapiro and Burchell, 2012).

Faktor pertama yang diprediksi memengaruhi kecemasan keuangan (financial anxiety) adalah pendapatan (income). Income adalah pendapatan bersih yang siap untuk dibelanjakan. Britt et al. (2016) dan Potter (2017) dalam penelitiannya mengemukakan bahwa income berperan sebagai aspek utama yang berkontribusi pada tingkat stress yang dialami seseorang. Individu dengan sumber penghasilan rendah bahkan tidak ada sama sekali, cenderung mengalami financial anxiety yang tinggi. Faktor kedua adalah utang (debt), yakni seluruh tanggungan finansial yang belum terselesaikan kepada pihak lain (Munawir 2004). Archuleta, Dale, and Spann (2013) dan Britt et al. (2016) menyatakan bahwa individu yang memiliki utang cenderung memiliki financial anxiety lebih tinggi daripada mereka yang tidak berutang.

Faktor ketiga ialah financial knowledge. Hearth, Kurtz, and Boone (2006) dalam Susan \& Djajadikerta (2017) menyatakan bahwa memiliki pengetahuan tentang bagaimana cara mengelola keuangan, seperti membelanjakan, menginvestasikan, menabung dan mengendalikan keuangan merupakan dasar penting agar mampu mengatur keuangan secara efektif. Archuleta et al. (2013); Britt et al. (2016) dan Pierceall and Keim (2007) melaporkan bahwa tidak terdapat pengaruh yang signifikan dari financial knowledge terhadap financial anxiety. Meski begitu, variabel ini masih layak untuk digunakan sebab masih terbatasnya penelitian yang menguji pengaruh financial knowledge terhadap financial anxiety. Selain itu, hingga penelitian ini ditulis, diketahui belum ada pengujian pengaruh dengan variabel serupa yang dilakukan di Indonesia, terlebih di Surabaya. Lokasi dan objek yang berbeda memungkinkan untuk memberi hasil pengujian yang berbeda.

Faktor terakhir adalah financial satisfaction, yang didefinisikan sebagai perasaan puas yang dirasakan atas income seseorang, serta kemampuan dalam menangani keadaaan darurat keuangan maupun memenuhi kebutuhan hidup dasar termasuk tingkat debt, serta jumlah tabungan, untuk tujuan hidup di masa depan (Hira and Mugenda, 1998). Terdapat pengaruh negatif financial satisfaction terhadap financial anxiety (Archuleta et al., 2013; Joo and Grable, 2004), yakni ketika seseorang memiliki rasa 
puas yang tinggi akan kondisi finansialnya, maka akan semakin menurunkan tingkat kecemasan keuangan mereka.

Tujuan dari penelitian ini adalah untuk membuktikan apakah variabel income, debt, financial knowledge dan financial satisfaction mampu memengaruhi financial anxiety. Keunikan dari penelitian ini ialah menjadi penelitian pertama di Indonesia khususnya di Surabaya, yang menggunakan financial anxiety atau kecemasan keuangan sebagai variabel terikat. Selain itu, penelitian yang menguji financial anxiety sebagai variabel terikat juga masih sangat terbatas. Sehingga diharapkan penelitian ini dapat menambah literatur mengenai financial anxiety. Terlebih, hingga saat ini, masih belum ditemukan adanya gap pada pengaruh financial knowledge terhadap financial anxiety. Karenanya, penelitian ini ingin membuktikan apakah di Indonesia, khususnya di Surabaya, juga tidak terdapat pengaruh financial knowledge terhadap financial anxiety.

\section{KAJIAN PUSTAKA DAN PENGEMBANGAN HIPOTESIS}

\section{Theory of Planned Behavior (TPB)}

Setiap perilaku yang dilakukan oleh seorang individu umumnya didasari oleh maksud atau niat untuk melakukannya (Ajzen, 1991). Niat mengindikasikan seberapa keras usaha yang dikerahkan dan seberapa besar keyakinan individu akan hasil yang dicapai dengan melakukan tindakan tersebut (Ajzen, 1991). Niat dilatarbelakangi oleh tiga faktor, yaitu sikap (attitude), norma subjektif (subjective norm), dan persepsi akan kontrol perilaku (perceived behavioral control) (Ajzen, 1991). Teori perilaku terencana atau TPB sangat relevan untuk menjelaskan variabel debt dan financial knowledge.

\section{Subjective Well-Being Theory (SWB)}

Cara pandang dan penilaian seorang individu terhadap kehidupannya akan memengaruhi bagaimana mereka merasa puas akan hidupnya (Diener, Suh, and Oishi, 1997). Penilaian tersebut berupa evaluasi kognitif dan afektif yang dirasakan atas hidupnya (Diener et al., 1999). Seseorang dapat dikatakan memiliki subjective well-being yang baik apabila penilaian atas kepuasan hidupnya positif, ditandai dengan rasa bahagia yang mendominasi emosionalnya. Sedangkan individu dengan subjective wellbeing yang rendah akan merasa tidak puas atas hidupnya, ditandai dengan sedikitnya kebahagiaan dan afeksi, sehingga emosionalnya didominasi oleh emosi negatif seperti depresi, kecemasan (anxiety), sedih, marah bahkan depresi (Diener et al., 1997). Teori ini relevan untuk menjelaskan variabel income dan financial satisfaction.

\section{Financial Anxiety}

Financial anxiety atau kecemasan keuangan menjadi penyumbang utama yang memengaruhi kecemasan seseorang, khususnya remaja, dengan melibatkan perasaan cemas hingga tertekan atas situasi keuangan yang sedang dihadapi (Archuleta et al., 2013). Seseorang dengan financial anxiety cenderung akan menghindari bahkan menolak hal-hal yang berkaitan dengan keuangan, seperti tidak membaca laporan bank, tidak memeriksa tingkat hutang maupun memikirkan upaya agar dapat membayar hutang di masa depan (Shapiro and Burchell, 2012). Berdasarkan penelitian yang dilakukan oleh Shapiro and Burchell (2012), financial anxiety dinyatakan dalam 4 poin skala likert dengan indikator berupa rasa cemas dan khawatir atas rekening bank, situasi keuangan, tabungan, utang, sumber keuangan, serta pengelolaan keuangan.

\section{Income}

Income berperan sebagai salah satu aspek yang berkontribusi pada tingkat stress yang dialami individu (Britt et al., 2016). Rendahnya income akan berdampak bukan hanya pada kesehatan keuangan dan mental individu saja, namun juga pada kesehatan fisik (Jones, Park, and Lefevor, 2018). Britt et al. (2016) menyatakan dalam penelitiannya, bahwa terdapat pengaruh income terhadap financial anxiety. Remaja dengan sedikit atau bahkan tanpa tabungan cenderung melaporkan financial anxiety yang tinggi. Menurut Badan Pusat Statistik tahun 2013 seperti yang diterapkan oleh Herdjiono and Damanik (2016), income dibedakan menjadi empat golongan, yakni golongan rendah (kurang dari 
Jehan Sekarkinasih. Faktor-Faktor yang Memengaruhi Kecemasan Keuangan pada Remaja Kota Surabaya

Rp1.500.000 per bulan); golongan sedang (Rp1.500.000 sampai Rp2.500.000 per bulan); golongan tinggi (Rp2.500.000 sampai Rp3.500.000 per bulan); dan golongan sangat tinggi (lebih dari Rp3.500.000 per bulan).

\section{Debt}

Menurut Munawir (2004) debt ialah seluruh kewajiban finansial kepada pihak lain yang belum terpenuhi. Aboagye \& Jung (2018) mendefinisikan debt sebagai segala bentuk pinjaman baik finansial maupun barang, yang diperoleh dari pihak lain. Penelitian menunjukkan sebagian besar remaja mengambil debt untuk melanjutkan pendidikan ke perguruan tinggi (Archuleta et al., 2013; Dwyer, McCloud, and Hodson, 2011; Perna, 2008). Rusdini (2020) menyatakan bahwa variabel debt diukur menggunakan yes or no binary scale. Opsi "yes" mendapat skor 1 artinya individu memiliki pinjaman atau debt, sedangkan opsi "no" mendapat skor 0 menandakan individu tidak memiliki pinjaman atau debt.

\section{Financial Knowledge}

Financial knowledge adalah bagian penting dari financial literacy yang didefinisikan sebagai sebuah ilmu pengetahuan yang dibutuhkan dalam mengelola keuangan sekaligus mengambil keputusan keuangan (Chen and Volpe, 1998). Definisi tersebut sejalan dengan Huston (2010) financial knowledge sebagai seluruh pengetahuan penting mengenai konsep keuangan, produk, serta layanan yang dibutuhkan dalam membuat keputusan keuangan secara tepat, seperti inflasi, bunga, dan resiko. Pengetahuan dapat diperoleh melalui pendidikan maupun pengalaman seseorang. Menurut Hakim (2017), indikator pengukuran financial knowledge meliputi pengetahuan mengenai investasi dan tabungan; asuransi; dan utang (Hakim 2017), dan dinyatakan dalam 4 poin skala likert.

\section{Financial Satisfaction}

Coşkuner (2016) mendefinisikan financial satisfaction sebagai sebuah penilaian bersifat subjektif yang mempresentasikan tingkat kepuasan dan rasa aman seseorang akan situasi keuangan mereka, sehingga terhindar dari perasaan financial anxiety. Financial satisfaction menimbulkan rasa puas atas income yang dimiliki seseorang, serta kemampuan yang baik dalam mengelola income tersebut dalam memenuhi kebutuhan hidupnya (Hira and Mugenda, 1998). Menurut Arifin (2018), financial satisfaction diukur menggunakan 4 poin skala likert melalui beberapa indikator, antara lain simpanan tabungan, besarnya utang, kondisi situasi keuangan saat ini, kemampuan individu dalam memenuhi kebutuhan hidup jangka panjang, simpanan dana darurat, Keterampilan dalam mengatur keuangan.

\section{Pengaruh antar Variabel}

Aboagye \& Jung (2018) mendefinisikan income sebagai jumlah atau seluruh uang yang dihasilkan oleh individu dari berbagai sumber. Income dijelaskan melalui teori subjective well-being, di mana persepsi seseorang atas income yang diterimanya mendasari tingkat kepuasan mereka atas hidupnya. Britt et al. (2016) dan Potter (2017) mengungkapkan bahwa income memiliki pengaruh negatif terhadap financial anxiety. Hal ini bermakna, ketika seseorang memiliki income yang baik maka akan semakin rendah kemungkinannya untuk memiliki financial anxiety, sebab diharapkan mereka telah mampu memenuhi kebutuhan hidup serta keinginannya. Berseberangan dengan itu, ketika seseorang memiliki income yang rendah maka akan besar kemungkinannya untuk memiliki financial anxiety, dikarenakan tidak adanya pendapatan untuk memenuhi kebutuhan hidupnya.

\section{H1 : Income berpengaruh terhadap financial anxiety.}

Debt atau utang ialah segala jenis kewajiban finansial kepada pihak lain yang belum terpenuhi (Munawir, 2004). Sebagian besar remaja mengambil pinjaman untuk melanjutkan pendidikan ke perguruan tinggi (Archuleta et al., 2013; Dwyer et al., 2011; Perna, 2008). Theory of planned behavior menjelaskan motif seseorang atas perilaku debt disebabkan oleh tekanan keuangan yang diikuti dengan terbatasnya anggaran, serta situasi kondisi lain yang semakin mendorongnya untuk berutang (Herispon, 2019). Britt et al. (2016) mengungkapkan bahwa debt memiliki pengaruh positif terhadap meningkatnya financial anxiety. Ketika seseorang dihadapkan dengan ketidaktersediaan sumber daya keuangan sementara kebutuhan semakin meningkat, maka timbul dorongan untuk 
berutang. Semakin tinggi tingkat utang seseorang dengan sumber keuangan yang rendah, semakin tinggi juga tingkat financial anxiety yang dimiliki.

\section{H2 : Debt berpengaruh terhadap financial anxiety.}

Pengetahuan akan keuangan yang dimiliki seorang individu mampu memengaruhi pemikiran, keputusan, serta proses pengelolaan keuangan individu tersebut (Chen and Volpe, 1998). Financial knowledge dijelaskan dalan theory of planned behavior melalui faktor norma subjektif, di mana tingkat pengetahuan keuangan seseorang berdampak pada bagaimana cara mereka mengelola keuangannya. Penelitian yang dilakukan oleh Archuleta et al. (2013), Britt et al. (2016) dan Pierceall and Keim (2007) tidak terdapat pengaruh financial knowledge terhadap financial anxiety. Hal tersebut dikarenakan individu bahkan tidak tahu bahwa mereka perlu merasa cemas akan situasi keuangannya. Penelitian akan ada tidaknya pengaruh financial knowledge terhadap financial anxiety masih layak untuk diuji, sebab masih terbatasnya studi yang membahas pengaruh kedua variabel tersebut. Lokasi dan objek penelitian yang berbeda memiliki kemungkinan untuk memberi hasil uji yang berbeda.

\section{H3 : Financial knowledge berpengaruh terhadap financial anxiety}

Rusdini (2020) menyatakan bahwa ketika seseorang merasa puas dan aman akan kondisi keuangannya maka dapat dikatakan mereka memiliki financial satisfaction yang baik. Subjective well-being theory mengaitkan evaluasi kepuasan hidup seseorang dengan emosi yang dirasakannya, di mana financial satisfaction berperan sebagai komponen penting dari keseluruhan life satisfaction dan life well-being (Plagnol, 2011). Terdapat pengaruh negatif financial satisfaction terhadap financial anxiety (Archuleta et al., 2013). Artinya, semakin tinggi financial satisfaction seseorang, maka semakin rendah financial anxiety yang mereka miliki. Hasil penelitian tersebut konsisten dengan penelitian sebelumnya yang dilakukan oleh Joo \& Grable (2004) mengenai dampak financial satisfaction terhadap tekanan finansial dan kesejahteraan finansial.

H4 : Financial satisfaction berpengaruh terhadap financial anxiety.

\section{METODE PENELITIAN}

Penelitian ini tergolong dalam penelitian kausalitas dengan metode kuantitatif. Sumber data yang digunakan adalah data primer, yakni penyebaran angket secara online menggunakan google forms. Variabel dependen yang digunakan pada penelitian ini ialah financial anxiety, dengan variabel independen berupa income, debt, financial knowledge, dan financial satisfaction. Populasi mencakup seluruh remaja Kota Surabaya berusia 15-24 tahun. Teknik simple random sampling dipilih sebagai teknik pengambilan sampel, dengan jumlah sampel diperoleh melalui perhitungan 28 indikator $\mathrm{x} 5=$ 140, kemudian dikalikan 10\% menghasilkan 154 responden.

Pada tahap pengambilan sampel penelitian, diambil sampel kecil terlebih dahulu yakni sebanyak 30 sampel untuk diuji validitas dan reliabilitasnya terhadap instrumen penelitian. Apabila data telah dinyatakan valid dan reliabel, selanjutnya dilakukan pengambilan sampel sebanyak 154 responden melalui penyebaran kuesioner online. Hasil perolehan data sampel diberi kode dan ditabulasi untuk selanjutnya dilakukan olah data statistik model regresi linier berganda menggunakan software SPSS. Tahap pengujian data yaitu uji validitas dan reliabilitas, uji asumsi klasik (meliputi uji normalitas, uji multikolinieritas, dan uji heterokedastisitas), uji regresi linier berganda, serta uji hipotesis yang berfungsi untuk membuktikan ada-tidaknya pengaruh antar variabel.

\section{HASIL DAN PEMBAHASAN}

\section{Uji Validitas}

Uji validitas dilakukan untuk variabel yang menggunakan alat ukur skala likert, yakni variabel financial knowledge, financial satisfaction, dan financial anxiety. Hasil pengujian pada kelompok 
Jehan Sekarkinasih. Faktor-Faktor yang Memengaruhi Kecemasan Keuangan pada Remaja Kota Surabaya

sampel kecil yakni sebanyak 30 responden, menunjukkan bahwa seluruh nilai $\mathrm{r}$ hitung setiap item pernyataan lebih besar daripada nilai $r$ tabel, di mana nilai $r$ tabel adalah 0,3494. Berdasarkan hasil pengujian terhadap 154 responden seperti yang tertera pada tabel 1, diketahui bahwa $r$ hitung di setiap item pernyataan memiliki nilai lebih besar dibandingkan dengan nilai $r$ tabel, yang mana nilai $r$ tabel sebesar 0.1572. Sesuai dengan Ghozali (2018:52), item pernyataan dinyatakan valid apabila nilai $r$ hitung lebih besar dari $r$ tabel. Karenanya, dapat ditarik kesimpulan bahwa seluruh item pernyataan yang digunakan dalam riset ini valid dan layak dijadikan alat ukur.

Tabel 1.

HASIL UJI VALIDITAS DAN RELIABILITAS

\begin{tabular}{|c|c|c|c|}
\hline Variable & Item & Pearson Correlation & Cronbach's Alpha \\
\hline \multirow{8}{*}{ Financial Knowledge } & FK1 & 0.608 & \multirow{8}{*}{0.831} \\
\hline & FK2 & 0.797 & \\
\hline & FK3 & 0.803 & \\
\hline & FK4 & 0.658 & \\
\hline & FK5 & 0.706 & \\
\hline & FK6 & 0.770 & \\
\hline & FK7 & 0.621 & \\
\hline & FK8 & 0.508 & \\
\hline \multirow{6}{*}{ Financial Satisfaction } & FS1 & 0.723 & \multirow{6}{*}{0.731} \\
\hline & FS2 & 0.745 & \\
\hline & FS3 & 0.491 & \\
\hline & FS4 & 0.559 & \\
\hline & FS5 & 0.720 & \\
\hline & FS6 & 0.735 & \\
\hline \multirow{12}{*}{ Financial Anxiety } & FA1 & 0.469 & \multirow{12}{*}{0.821} \\
\hline & FA2 & 0.564 & \\
\hline & FA3 & 0.666 & \\
\hline & FA4 & 0.537 & \\
\hline & FA5 & 0.381 & \\
\hline & FA6 & 0.605 & \\
\hline & FA7 & 0.695 & \\
\hline & FA8 & 0.615 & \\
\hline & FA9 & 0.690 & \\
\hline & FA10 & 0.717 & \\
\hline & FA11 & 0.595 & \\
\hline & FA12 & 0.475 & \\
\hline
\end{tabular}

Sumber: Output SPSS (data diolah)

\section{Uji Reliabilitas}

Tabel 1, nilai cronbach's alpha pada hasil uji reliabilitas untuk skala likert variabel financial knowledge, financial satisfaction, dan financial anxiety seluruhnya lebih besar dari 0,70. Hal ini sesuai dengan Ghozali (2018:46), di mana item pernyataan suatu variabel dinyatakan reliabel apabila nilai cronbach's alpha $>0,70$. Oleh karena itu, data sudah sesuai dengan kriteria sehingga seluruh variabel dinyatakan reliabel.

\section{Uji Normalitas}

Terdapat dua metode yang digunakan dalam uji normalitas di penelitian ini. Pertama, analisis grafik melalui grafik normal probability plot, yang mana hasil dari analisis menunjukkan bahwa persebaran 
data terdistribusi disekitar garis diagonal dan mengikuti grafik histogramnya. Metode kedua adalah uji statistik berupa uji kolmogorov-smirnov. Hasil uji menunjukkan nilai uji 0,767, dengan signifikansi sebesar 0,598 yang mana lebih besar dari 0,05 . Berdasarkan analisis grafik dan uji kolmogorovsmirnov yang telah dilakukan, data residual telah berdistribusi normal.

\section{Uji Multikolinieritas}

Ketentuan untuk lolos uji multikolinieritas adalah apabila nilai tolerance $\geq 0,10$ dan nilai VIF $\leq 10$ (Ghozali, 2018:108). Hasil uji pada variabel penelitian ini secara keseluruhan menunjukkan nilai tolerance berkisar pada angka 0,8-0,9 dan nilai VIF seluruhnya bernilai 1 , sehingga tidak terjadi multikolinieritas pada model regresi penelitian ini.

\section{Uji Heteroskedastisitas}

Uji heteroskedastisitas dilakukan dengan menganalisis grafik scatterplot dan uji spearman. Analisis pada grafik scatterplot diketahui bahwa titik-titik data tersebar secara acak, baik di atas maupun di bawah angka nol pada sumbu Y. Selanjutnya pada uji spearman, nilai signifikansi seluruh variabel diketahui $>0,05$. Artinya, tidak terjadi heteroskedastisitas pada penelitian ini.

\section{Regresi Linier Berganda}

Hasil uji regresi linier berganda pada tabel 2 menunjukkan nilai signifikansi dari setiap variabel independen > 0,05. Hal ini mengindikasikan bahwa tidak terdapat pengaruh baik dari variabel income, debt, financial knowledge maupun financial satisfaction terhadap financial anxiety pada remaja Kota Surabaya.

Tabel 2.

\section{HASIL UJI REGRESI LINIER BERGANDA}

\begin{tabular}{llccc}
\hline & Model & $\begin{array}{c}\text { Unstandardized } \\
\text { Coefficients }\end{array}$ & Prob. & Sig. \\
\hline $1 \quad$ (Constant) & 25.279 & 6.488 & .000 \\
& Income & -.550 & -.933 & .352 \\
& Debt & -.454 & -.388 & .698 \\
Financial Knowledge & .064 & .550 & .583 \\
& Financial Satisfaction & .117 & .713 & .477 \\
& F Test & & .430 & .787 \\
Adj. R Square & -.015 & & \\
\hline
\end{tabular}

Sumber: Output SPSS (data diolah)

\section{Uji statistik F}

Uji Statistik F dilakukan untuk mengetahui kelayakan model. Hasil uji statistik F pada tabel 2, menunjukkan nilai $\mathrm{F}$ hitung $0,430<\mathrm{F}$ tabel 2,437 dengan nilai signifikansi $0,787>0,05$. Hal ini mengindikasikan bahwa secara bersama-sama, seluruh variabel independen pada penelitian ini tidak dapat memengaruhi financial anxiety, sehingga model penelitian dinyatakan tidak layak.

\section{Pembahasan}

Uji statistik $\mathrm{F}$ menunjukkan bahwa income tidak terbukti memiliki pengaruh terhadap financial anxiety. Hasil uji ini merupakan temuan baru dan belum memiliki dasar penelitian terdahulu. Hasil penelitian tidak sesuai dengan subjective well being theory yang menyatakan semakin tinggi income seseorang, maka akan semakin terhindar dari emosi negatif, seperti kecemasan akibat situasi keuangan. Penelitian yang menganalisis pengaruh income terhadap financial anxiety masih sangat sedikit, dilakukan oleh Archuleta, Dale, and Spann (2013) dan Britt et al. (2016) yang menyatakan income memiliki pengaruh negatif terhadap financial anxiety.

Hasil pengolahan data juga menunjukkan tidak terdapat pengaruh debt terhadap financial anxiety. Hasil ini tidak sejalan dengan theory of planned behavior yang menjelaskan motif seseorang atas 
Jehan Sekarkinasih. Faktor-Faktor yang Memengaruhi Kecemasan Keuangan pada Remaja Kota Surabaya

perilaku debt didasari oleh tekanan keuangan yang diikuti dengan terbatasnya anggaran. Hasil penelitian ini didukung oleh Archuleta, Dale, and Spann (2013), yang mengungkapkan bahwa total keseluruhan utang tidak memiliki pengaruh terhadap kecemasan keuangan. Meski tidak berpengaruh, namun debt merupakan faktor penting untuk memprediksi financial anxiety.

Financial knowledge diketahui tidak memiliki pengaruh signifikan terhadap financial anxiety. Hasil ini sejalan dengan theory of planned behavior melalui faktor norma subjektif, di mana tingkat pengetahuan keuangan seseorang berdampak pada bagaimana cara mereka mengelola keuangannya. Hasil penelitian ini sejalan dengan Archuleta et al. (2013), Britt et al. (2016) dan Pierceall and Keim (2007) yang menyatakan financial knowledge tidak berpengaruh signifikan terhadap financial anxiety.

Financial satisfaction tidak terbukti berpengaruh signifikan terhadap financial anxiety. Hal ini tidak searah dengan subjective well being theory, di mana financial satisfaction berperan sebagai komponen penting dari keseluruhan kepuasan serta kesejahteraan hidup. Hasil penelitian tidak sejalan dengan Archuleta, Dale, and Spann (2013) yang menyatakan semakin tinggi financial satisfaction seseorang, akan semakin terhindar dari financial anxiety. Hingga artikel ini ditulis, diketahui penelitian yang menganalisis pengaruh financial satisfaction terhadap financial anxiety baru dilakukan satu kali, yakni oleh Archuleta, Dale, and Spann (2013) dengan hasil berpengaruh positif. Sehingga, hasil penelitian ini merupakan temuan baru dan masih belum memiliki dasar penelitian terdahulu.

Meskipun hasil dari penelitian ini belum mampu membuktikan adanya pengaruh income, debt, financial knowledge dan financial satisfaction terhadap financial anxiety, namun berhasil menciptakan temuan-temuan baru yang berbeda dari peneliti terdahulu. Temuan baru ini dapat terjadi karena penelitian untuk mengetahui faktor-faktor yang berpengaruh terhadap financial anxiety masih sangat baru dan jarang dilakukan. Terlebih, belum ditemui penelitian terdahulu yang meneliti financial anxiety sebagai variabel dependen di Indonesia. Hal ini memunculkan dugaan bahwa responden masih belum memahami dengan baik mengenai financial anxiety, sehingga menyebabkan penelitian tidak mendapatkan hasil yang optimal.

\section{KESIMPULAN}

Hasil penelitian menunjukkan income, debt, financial knowledge serta financial satisfaction tidak terbukti berpengaruh terhadap financial anxiety pada remaja di Kota Surabaya. Temuan tersebut disebabkan masih sedikitnya literasi yang membahas mengenai financial anxiety, terlebih di Indonesia. Hal ini diduga menyebabkan tingkat pemahaman responden terhadap financial anxiety masih belum baik, sehingga berdampak pada hasil penelitian yang tidak optimal.

Keterbatasan penelitian ialah jumlah sampel yang sedikit, dengan jangkauan penyebaran kuisioner yang kurang merata untuk wilayah Kota Surabaya. Terlebih, penyebaran tersebut hanya dilakukan secara online dikarenakan adanya pandemi Covid-19, sehingga tidak bisa secara leluasa menjelaskan maksud pernyataan mengenai financial anxiety yang harus diisi oleh responden, serta melakukan sesi wawancara untuk mendapat hasil yang lebih optimal. Selain itu, masih sedikitnya literatur yang meneliti faktor-faktor financial anxiety menyebabkan referensi dalam penelitian ini juga masih sangat terbatas.

Implikasi dari hasil penelitian ini, bagi remaja diharapkan dapat memperdalam pengetahuan keuangan serta bagaimana mengelolanya, sehingga terhindar dari kecemasan keuangan di masa sekarang maupun di masa depan. Bagi peneliti selanjutnya, diharapkan dapat digunakan sebagai bahan referensi untuk penelitian selanjutnya, agar penelitian mengenai financial anxiety dapat dilakukan lebih mendalam agar dapat meningkatkan kewaspadaan masyarakat, khususnya remaja, akan financial anxiety. Direkomendasikan untuk penelitian selanjutnya agar melakukan penelitian kembali di Kota Surabaya dengan menyebarkan kuisioner secara offline disertai dengan memberi penjelasan mengenai financial anxiety dan melakukan wawancara, memperbanyak jumlah sampel, serta melakukan pengambilan sampel dengan memperhatikan tingkat persebarannya. Hal ini bertujuan agar bisa menghasilkan output yang berbeda dan lebih akurat. 


\section{DAFTAR PUSTAKA}

Aboagye, Judith, and Ji Young Jung. (2018). Debt Holding, Financial Behavior, and Financial Satisfaction. Journal of Financial Counseling and Planning 29(2):208-18. doi: 10.1891/10523073.29.2.208.

Ajzen, Icek. (1991). The Theory of Planned Behavior Organizational Behavior and Human Decision Processes. Organizational Behavior and Human Decision Processes 50(2):179-211.

Archuleta, Kristy L., Anita Dale, and Scott M. Spann. (2013). College Students and Financial Distress: Exploring Debt, Financial Satisfaction, and Financial Anxiety. Journal of Financial Counseling and Planning 24(2):50-62.

Arifin, A. Z. (2018). Influence Factors Toward Financial Satisfaction with Financial Behavior as Intevening Variable on Jakarta Area Workforce. European Research Studies Journal 21(1), 90103.

BPS. (2019a). Proyeksi Penduduk Kota Surabaya Menurut Jenis Kelamin dan Kelompok Umur Tahun 2019. Badan Pusat Statistik. https://surabayakota.bps.go.id/dynamictable/2018/04/18/23/proyeksi-penduduk-kota-surabayamenurut-jenis-kelamin-dan-kelompok-umur-tahun-2019.html. Ddiakses pada 21 Januari 2021

BPS. (2019b). Proyeksi Penduduk Menurut Kabupaten/Kota dan Jenis Kelamin Di Jawa Timur Tahun 2019. Badan Pusat Statistik. https://jatim.bps.go.id/dynamictable/2018/02/05/315/proyeksipenduduk-menurut-kabupaten-kota-dan-jenis-kelamin-di-jawa-timur-2019-.html. Diakses pada 21 Januari 2021

Britt, Sonya L., Melanie R. Mendiola, Gregory H. Schink, Racquel H. Tibbetts, and Scott H. Jones. (2016). Financial Stress, Coping Strategy, and Academic Achievement of College Students. Journal of Financial Counseling and Planning 27(2):172-83. doi: 10.1891/10523073.27.2.172.

Chen, Haiyang, and Ronald P. Volpe. (1998). An Analysis of Personal Financial Literacy among College Students. Financial Service Review 7(2):107-28. doi: 10.1016/S1057-0810(99)800067.

Coşkuner, Selda. (2016). Understanding Factors Affecting Financial Satisfaction: The Influence of Financial Behavior, Financial Knowledge and Demographics. Imperial Journal of Interdisciplinary Research 2(5):377-85.

Degnan, Kathryn A., Alisa N. Almas, and Nathan A. Fox. (2010). Temperament and the Environment in the Etiology of Childhood Anxiety. Journal of Child Psychology and Psychiatry and Allied Disciplines 51(4):497-517. doi: 10.1111/j.1469-7610.2010.02228.x.

Diener, Ed, Eunkook Suh, Richard E. Lucas, and Heidi L. Smith. (1999). Subjective Weil-Being: Three Decades of Progress. Psychological Bulletin 125(2):276-302. doi: 10.1037/00332909.125.2.276.

Diener, Ed, Eunkook Suh, and Shigehiro Oishi. (1997). Recent Findings on Subjective Well-Being. Indian Journal of Clinical Psychology 24(1):25-41.

Dixon, Wayne A., Kimberly G. Rumford, P. Paul Heppner, and Barbara J. Lips. (1992). Use of Different Sources of Stress to Predict Hopelessness and Suicide Ideation in a College Population. Journal of Counseling Psychology 39(3):342-49. doi: 10.1037/00220167.39.3.342. 
Jehan Sekarkinasih. Faktor-Faktor yang Memengaruhi Kecemasan Keuangan pada Remaja Kota Surabaya

Dwyer, Rachel E., Laura McCloud, and Randy Hodson. (2011). Youth Debt, Mastery, and SelfEsteem: Class-Stratified Effects of Indebtedness on Self-Concept. Social Science Research 40(3):727-41. doi: 10.1016/j.ssresearch.2011.02.001.

Elvira, Sylvia Detri, and Gitayanti Hadisukanto, eds. (2010). Buku Ajar Psikiatri Universitas Indonesia. Edisi Keti. Jakarta: Badan Penerbit Fakultas Kedokteran Universitas Indonesia.

Ghozali, Imam. (2018). Aplikasi Analisis Multivariate dengan Program IBM SPSS 25. 9th ed. Semarang: Badan Penerbit Universitas Diponegoro.

Hakim, I. M. (2017). Pengaruh Financial Knowledge, Income, dan Financial Attitude terhadap Financial Management Behaviour pada Pengusaha Bordir Kota Tasikmalaya. Jurnal Manajemen Universitas Universitas Siliwangi 6(2).

Herdjiono, Irine, and Lady Angela Damanik. (2016). Pengaruh Financial Attitude, Financial Knowledge, Parental Income terhadap Financial Management Behavior. Jurnal Manajemen Teori Dan Terapan| Journal of Theory and Applied Management 9(3):226-41. doi: 10.20473/jmtt.v9i3.3077.

Hira, Tahira K., and Olive M. Mugenda. (1998). Predictors of Financial Satisfaction: Differences between Retirees and Non-Retirees. Journal of Financial Counseling and Planning 9(2):75-84. doi: 10.1.1.576.3209.

Huston, Sandra J. (2010). Measuring Financial Literacy. Journal of Consumer Affairs 44(2):296-316. doi: 10.1111/j.1745-6606.2010.01170.x.

Jones, Payton J., So Yeon Park, and G. Tyler Lefevor. (2018). Contemporary College Student Anxiety: The Role of Academic Distress, Financial Stress, and Support. Journal of College Counseling 21(3):252-64. doi: 10.1002/jocc.12107.

Joo, So-hyun, and John E. Grable. (2004). An Exploratory Framework of the Determinants of Financial Satisfaction. Journal of Business Ethics 51(1):31-39. doi: 10.1023/B.

Munawir. (2004). Analisis Laporan Keuangan. 4th ed. Jogjakarta: Liberty.

Musabiq, Sugiarti, and Isqi Karimah. (2018). Gambaran Stress dan Dampaknya pada Mahasiswa. Insight: Jurnal Ilmiah Psikologi 20(2):74. doi: 10.26486/psikologi.v20i2.240.

Oman, Doug, Shauna L. Shapiro, Carl E. Thoresen, Thomas G. Plante, and Tim Flinders. (2008). Meditation Lowers Stress and Supports Forgiveness among College Students: A Randomized Controlled Trial. Journal of American College Health 56(5):569-78. doi: 10.3200/JACH.56.5.569-578.

Perna, Laura W. (2008). Understanding High School Students' Willingness to Borrow to Pay College Prices. Research in Higher Education 49(7):589-606. doi: 10.1007/s11162-008-9095-6.

Pierceall, Emily A., and Marybelle C. Keim. (2007). Stress and Coping Strategies among Community College Students. Community College Journal of Research and Practice 31(9):703-12. doi: $10.1080 / 10668920600866579$.

Plagnol, Anke C. (2011). Financial Satisfaction over the Life Course: The Influence of Assets and Liabilities. Journal of Economic Psychology 32(1):45-64. doi: 10.1016/j.joep.2010.10.006.

Potter D., Jayne D., and Britt S. (2017). Financial Anxiety of First Generation College Students.American Council on Consumer Interests 63(number):1-8. 
Rahmawati, Mega Nur, Slamet Rohaedi, and Sri Sumartini. (2019). Tingkat Stres dan Indikator Stres pada Remaja yang Melakukan Pernikahan Dini. Jurnal Pendidikan Keperawatan Indonesia 5(1):25-33. doi: 10.17509/jpki.v5i1.11180.

Riskesdas. (2020). Laporan Provinsi Jawa Timur Riskesdas 2018. https://ejournal2.litbang.kemkes.go.id/index.php/lpb/article/view/3752. Diunduh pada 22 Januari 2021

Ross, S. E. B., Niebling, C., \& Heckert, T. M. (1999). Sources of Stress among College Students. College Students Journal, 33(2), 312-318.

Rusdini, Dinda Arfiana. (2020). Faktor yang Memengaruhi Financial Satisfaction pada Masyarakat Kabupaten Pamekasan. Jurnal Ilmu Manajemen 9(1), 1-9.

Shapiro, Gilla K., and Brendan J. Burchell. (2012). Measuring Financial Anxiety. Journal of Neuroscience, Psychology, and Economics 5(2):92-103. doi: 10.1037/a0027647.

Susan, Marcellia, and Hamfri Djajadikerta. (2017). Understanding Financial Knowledge, Financial Attitude, and Financial Behavior of College Students in Indonesia. Advanced Science Letters 23(9):8762-65. doi: 10.1166/asl.2017.9966.

World Health Organization. (2018). Adolescent Health in the South-East Asia Region. https://www.who.int/southeastasia/health-topics/adolescent-health. Diakses pada 19 Januari 2021.

Yanti, Supri, Erlamsyah Erlamsyah, and Zikra Zikra. (2013). Hubungan antara Kecemasan dalam Belajar dengan Motivasi Belajar Siswa. Konselor 2(1):283-88. doi: 10.24036/02013211242-000 .

Yulianti, Rina. (2010). Dampak yang Ditimbulkan Akibat Perkawinan Usia Dini. Pamator Journal $3(1): 1-5$. 